\title{
Safety of Monitoring Exercise for Early Hospital- based Cardiac Rehabilitation
}

\author{
Chul Kim, M.D., Ph.D., Chang Jin Moon, M.D., Min Ho Lim, M.D. \\ Department of Rehabilitation Medicine, Sanggye Paik Hospital, Inje University College of Medicine, Seoul 139-707, Korea
}

\begin{abstract}
Objective To survey the cardiovascular complications induced by cardiac monitoring exercise during 10 years of our cardiac rehabilitation (CR) clinic and report on the safety of monitoring exercise training for early hospitalbased CR.

Method All cardiac patients who participated in our exercise program from January 2000 through December 2009 were recruited as study subjects. We stratified the exercise risks of cardiac events and conducted the monitoring exercise with individualized prescriptions. We measured all cardiac complications, including death, symptoms, abnormal hemodynamic responses, and electrocardiogram (ECG) abnormality during exercise training, for 10 years. A total of 975 patients ( $68 \%$ male; mean age, $58.9 \pm 10.6)$ were included in this study. Initial indications for CR were recent percutaneous transluminal coronary angioplasty (PTCA) (75\%), post-cardiac surgery (coronary bypass graft, $13.2 \%)$, valvular surgery and other cardiac surgery (4.2\%), and others (7.6\%).

Results The study population underwent 13,934 patient-hours of monitoring exercise. No death, cardiac arrest or acute myocardial infarction (AMI) occurred during exercise (0/13,934 exercise-hours). Fifty-nine patients experienced 70 cardiovascular events during the 13,934 exercise-hours (1/199 exercise-hours); there were 17 cases of angina only ( $1 / 820$ exercise-hours), 31 cases of ECG abnormalities only ( $1 / 449$ exercise-hours), 12 cases of angina with ECG abnormalities (1/1,161 exercise-hours), and 10 cases of abnormal hemodynamic responses (1/1,393 exercise-hours).

Conclusion Early hospital-based CR is safe enough that no death, cardiac arrest or AMI occurred during the 13,934 patient-hours of monitoring exercise. However, risk stratification for exercise-induced cardiovascular events, proper exercise prescriptions, and intensive ECG monitoring are required prior to initiation of the monitoring exercise.
\end{abstract}

Key Words Cardiovascular disease, Exercise, Myocardial infarction, Rehabilitation

Received August 22, 2011; Accepted March 5, 2012

Corresponding author: Chang Jin Moon

Department of Rehabilitation Medicine, Sanggye Paik Hospital, Inje University College of Medicine, 761-1, Sanggye 7-dong, Nowon-gu, Seoul 139-707, Korea

Tel: +82-2-950-1134, Fax: +82-2-935-3076, E-mail: ckim@paik.ac.kr

(c) This is an open-access article distributed under the terms of the Creative Commons Attribution Non-Commercial License (http:// creativecommons.org/licenses/by-nc/3.0) which permits unrestricted noncommercial use, distribution, and reproduction in any medium, provided the original work is properly cited.

Copyright (๑) 2012 by Korean Academy of Rehabilitation Medicine

\section{INTRODUCTION}

Cardiac rehabilitation for acute myocardial infarction patients is known not only to improve cardiopulmonary functions during exercise and the quality of life and psycho-social functions, but also allows for the more efficient management of risk factors. It reduces the mortality rate due to deaths from cardiovascular diseases and from all causes in general. In addition, it lowers the recurrence 
rate of acute myocardial infarction and the revascularization (by surgery or PTCA) rate. ${ }^{1-4}$ Also, according to previous studies, long-term cardiac rehabilitation either slows down the advance of atherosclerosis or decreases the severity of the disease. ${ }^{5,6}$

Although many cardiac disease patients may have benefited from the above-mentioned effects through cardiac rehabilitation, the actual cases of request for cardiac rehabilitation are not very common. According to multi-institutional studies of 31 hospitals in the state of Queensland in Australia for a year (between 1999 and 2000), the cases actually requiring cardiac rehabilitation were 8,895 (59\%) out of 15,186 patients who had been diagnosed with cardiac disease and discharged from the hospital, while requests for cardiac rehabilitation were made for 4,346 patients (29\%) among the $15,186 .{ }^{7}$ Frequently, the cardiac disease patients who did not request cardiac rehabilitation restricted their exercise due to concerns about cardiovascular complications occurring during exercise.

While the need and the effects of cardiac rehabilitation are so well known as not to produce any disagreement, it is true that not only the patients who request cardiac rehabilitation but also the medical team who are involved in the cardiac rehabilitation have concerns regarding cardiovascular-related complications that may occur during monitoring exercises. The present institution has reported on cardiovascular-related complications that occurred during monitoring exercises for a year beginning in January $1999 .{ }^{8}$ The present researchers investigated the cardiovascular-related complications that occurred during monitoring exercises for a 10 -year period to assess the safety of early hospital-based monitoring exercises.

\section{MATERIALS AND METHODS}

\section{Study subjects}

All cardiac disease patients who participated in the monitoring exercises at the cardiac rehabilitation clinic from January 2000 to December 2009 were included in the study. Out of a total of 975 patients, 663 patients (67.5\%) were male, with a mean age of $58.9 \pm 10.6$ years. Among them, 731 patients $(75.0 \%)$ had received a percutaneous transluminal coronary angioplasty (PTCA), while 57 patients $(5.8 \%)$ had received conservative therapy including medication after a coronary angiography, 129 patients (13.2\%) had undergone coronary artery bypass graft (CABG) and 41 patients $(4.2 \%)$ had had other cardiac operations such as valvular surgery. Eight patients $(0.8 \%)$ out of the other 17 were under medical treatment for cardiomyopathy, 6 patients $(0.6 \%)$ for peripheral artery disease, and 3 patients $(0.3 \%)$ for arrhythmia (Table 1). Intercurrent patients with stroke, cancer or neuromuscular skeletal system diseases for whom faithful implementation of cardiac rehabilitation would be difficult were excluded from the study.

\section{Study method}

Through a prior graded exercise test, the risk stratification of cardiac attack was investigated, and follow-up measures were examined retrospectively through clinical records for patients in whom cardiovascular-related complications, abnormal hemodynamic responses and symptoms, electrocardiogram abnormalities or any other cardiovascular-related abnormalities had occurred.

Table 1. Demographic Data of Subjects Patients

\begin{tabular}{lc}
\hline Number of subjects & 975 \\
Gender (male/female) & $663: 312$ \\
Age (years) & $58.9 \pm 10.6$ \\
Reason for referral & $731(75.0 \%)$ \\
\hline PTCA after AMI & $129(13.2 \%)$ \\
\hline CABG & $57(5.8 \%)$ \\
\hline AMI & $36(3.7 \%)$ \\
\hline Artificial valve implantation & $5(0.5 \%)$ \\
\hline Other cardiac surgery & $17(1.7 \%)$ \\
\hline Others* & \\
Patients with history of & $578(59.3 \%)$ \\
\hline Diabetes & $239(24.5 \%)$ \\
\hline Hypertension & $354(36.3 \%)$ \\
\hline Previous smoker & $36(3.7 \%)$ \\
\hline Current smoker & \\
\hline Drug therapy & $581(59.6 \%)$ \\
\hline Beta-blocking agents & $214(21.9 \%)$ \\
\hline Calcium antagonists & $772(79.2 \%)$ \\
\hline Lipid lowering agents
\end{tabular}

Values are mean \pm standard deviation or the number of cases

PTCA: Percutaneous transluminal coronary angioplasty, AMI: Acute myocardial infarction, CABG: Coronary artery bypass graft

*Diverse medical conditions: cardiomyopathy, peripheral arterial occlusive disease, pacemaker or defibrillator implantation, arrhythmia 


\section{Cardiac rehabilitation program}

Risk assessments of cardiac attack resulting from exercise were performed on the patients participating in cardiac rehabilitation by a prior graded exercise test. The monitoring exercises in the hospital were done under ECG monitoring and were carried out according to exercise prescriptions that included strict management instructions on risk factors for the initial 6 to 8 weeks. Before starting the monitoring exercises, all patients received a symptom-limited graded exercise test using the modified Bruce protocol. For the graded exercise testing, 12-channel real-time ECG tester for exercise load testing Q4500 (Quinton Instrument Co., Boston, USA), automatic blood pressure and pulse measuring instrument Model 412 (Quinton Instrument Co., Boston, USA), and treadmill for graded exercise testing Medtrack ST 55 (Quinton Instrument Co., Boston, USA) were employed. Exercise prescriptions were issued based on the results of the initial graded exercise test. The exercise time for each session consisted of 10 minutes for the preparatory exercise, 30 minutes for the main exercise, and 10 minutes for the cooling down exercise for a total of 50 minutes. The exercise intensity in terms of the target heart rate increased stepwise from $40 \%$ to $85 \%$ of the heart rate reserve values as calculated from the graded exercise test results. The rate of perceived exertion (RPE) during the monitoring exercises was maintained at 13-14 (a little difficult). Throughout the monitoring exercise, real-time ECG, heart rate, and blood pressure were monitored, the patient's perceived symptoms frequently checked, and the indices recorded.

Table 2. Cardiovascular Events during Monitoring Exercise

\begin{tabular}{lc}
\hline & \multicolumn{1}{c}{ Sessions of exercise } \\
\hline $\begin{array}{l}\text { Angina without ECG abnor- } \\
\text { mality }\end{array}$ & $17(1 / 820$ exercise hours $)$ \\
ECG abnormalities without & $31(1 / 449$ exercise hours $)$ \\
symptom & \\
$\begin{array}{l}\text { Angina with ECG abnormali- } \\
\text { ties }\end{array}$ & $12(1 / 1,161$ exercise hours $)$ \\
$\begin{array}{l}\text { Abnormal hemodynamic } \\
\text { responses }\end{array}$ & $10(1 / 1,393$ exercise hours $)$ \\
\hline $\begin{array}{l}\text { ECG: Electrocardiogram } \\
\end{array}$
\end{tabular}

ECG: Electrocardiogram

\section{RESULTS}

Cardiovascular-related complications during monitoring exercise

Not a single incident of fatal cardiovascular-related complication such as death, cardiac arrest, or acute myocardial infarction occurred during the monitoring exercises (0/13,934 exercise hours). However, there were 70 cases of cardiovascular-related abnormal events in 59 patients (1/199 exercise hours), of which 17 cases (1/820 exercise hours) were angina pectoris only without ECG abnormality. There were 31 cases of ECG abnormality without a symptom (1/449 exercise hours), 12 cases of both angina pectoris and ECG abnormality $(1 / 1,161$ exercise hours), and 10 cases of abnormal hemodynamic response (1/1,393 exercise hours) (Table 2$)$.

Characteristics and risk classification of cardiac attacks for patients with cardiovascular-related abnormalities

Among 59 patients for whom cardiovascular-related abnormalities were observed during exercise, 41 patients (69. 5\%) were male with a mean age of $56.5 \pm 12.4$ years. Prior to initiation of the cardiac rehabilitation, 53 patients $(89.8 \%)$ had received a PTCA, with an average remaining stenosis rate of $23.5 \pm 8.4 \%$, and an average ejection fraction of the left ventricle of $46.3 \pm 21.2 \%$; 34 patients (57.6\%) had lesions of the left anterior descending artery, and 6 patients $(10.2 \%)$ had CABG (Table 3$)$. Classification

Table 3. Demographic Data of Patients who Developed Cardiovascular Events during Monitoring Exercise

\begin{tabular}{lc}
\hline Number of subjects & 59 \\
Gender (male/female) & $41: 18$ \\
Age (years) & $56.5 \pm 12.4$ \\
Reason for referral & $53(89.8 \%)$ \\
PTCA after AMI & $6(10.2 \%)$ \\
\hline CABG & \\
Cardiac indices in patients after PTCA & $23.5 \pm 8.4 \%$ \\
Remaining stenosis & $46.3 \pm 21.2 \%$ \\
LVEF & $34(57.6 \%)$ \\
\hline
\end{tabular}

Values are mean \pm standard deviation or the number of cases

PTCA: Percutaneous transluminal coronary angioplasty, CABG: Coronary artery bypass graft, LVEF: Ejection fraction of left ventricle, LAD: Left anterior descending artery 
of these 59 patients according to exercise risk stratification $^{9,10}$ showed 45 patients ( $76.3 \%$ ) belonged to the high risk group, 8 patients (13.5\%) to the middle risk group, and 6 patients $(10.2 \%)$ to the low risk group (Table 4 ).

Follow-up measures for patients with cardiovascularrelated abnormalities

Out of the 59 patients who had problems during monitoring exercise, 36 had their problems resolved through confirmation angiography and adjustment of cardiovascular-related medications. On angiography, 20 patients showed restenosis and received PTCA for reperfusion. One patient who exhibited atrial fibrillation and ventricular tachycardia received internal defibrillator insertion, and another patient showing bradycardia and syncope underwent coronary artery bypass graft. The patient with ventricular tachycardia was prescribed Verapamil injection intravenously and a dosage of a calcium channel blocker (Table 5). All 59 patients were able to participate in the monitoring exercises again, and have been receiving regular follow-up while continuously participating in cardiac rehabilitation programs of their local communities.

\section{DISCUSSION}

Cardiac rehabilitation programs are gradually increasing in importance as interest in cardiovascular-related diseases rises. ${ }^{11}$ Although 3 private university hospitals in a metropolitan area and one hospital specializing in cardiac diseases were the only medical institutions domestically operating cardiac rehabilitation programs before 2007, 5 private university hospitals in a metropolitan area, one hospital specializing in cardiac disease, and 9 local university hospitals now operate cardiac rehabilita-

Table 4. Exercise Risk Stratifications* in Patient who Developed Cardiovascular Events during Monitoring Exercise

\begin{tabular}{lc}
\hline \multicolumn{1}{c}{ Risk } & Sessions of exercise (\%) \\
\hline High & $52(75.5)$ \\
Intermediate & $10(14.3)$ \\
Low & $7(10.2)$ \\
\hline
\end{tabular}

*Exercise Risk Stratification according to the guidelines of AACVPR (American Association of Cardiovascular \& Pulmonary Rehabilitation), ACC (American College of Cardiology), and AHA (American Heart Association) tion programs. Under a project by the Ministry of Health and Welfare regional cardiocerebrovascular centers were created and the cardiac rehabilitation programs were implemented in these institutions. Consequently, interest in cardiovascular-related complications occurring during monitoring exercises and the safety of early hospitalbased monitoring exercises for cardiac rehabilitation has increased.

The monitoring exercises, that last for 6-8 weeks, are aerobic exercises of the entire body using a treadmill and a bicycle ergometer. Risk stratifications were for Cardiac disease patients were stratified according to risk, and exercise intensities were set at $40-85 \%$ of the calculated heart rate reserve values based on the patient's heart rates recorded from the graded exercise tests. Here, monitoring exercises were absolutely required for the patients in the high risk group, and also for the patients in whom the conditions of the blood vessels that did not receive an intervention were not favorable.

As for complications that may be encountered during monitoring exercises, cardiac arrest, acute myocardial infarction, angina pectoris, arrhythmia, ECG abnormality, hemodynamic abnormal response are among the complications that may occur, and of these the complications that led to death the most commonly were cardiac arrest and myocardial infarction. According to a 1977 report by 30 cardiac rehabilitation institutions in the North America region from 1960 through 1977, there was one cardiac arrest per 32,593 hours, one death per 166,402 hours, and one myocardial infarction per 232,805 hours. ${ }^{12}$

A report in 1986 indicated that one major cardiovascular-related complication occurred per 81,101 hours, and

Table 5. Management after Cardiovascular Events

\begin{tabular}{llc}
\hline \multicolumn{1}{c}{ Events } & \multicolumn{1}{c}{ Management } & $\begin{array}{c}\text { Number } \\
(\mathbf{\%})\end{array}$ \\
\hline Angina or ST depression & CAG+medication & $36(61.0)$ \\
Angina or ST depression & CAG+PTCA & $20(33.9)$ \\
AF with VT & ICD insertion & $1(1.7)$ \\
Syncope with bradycardia & CABG & $1(1.7)$ \\
VT & Verapamil IV+CCB & $1(1.7)$ \\
\hline
\end{tabular}

CAG: Coronary angiography, Medication: Managed by only adjustment of medication, PTCA: Percutaneous transluminal coronary angioplasty, AF: Atrial fibrillation, VT: Ventricular tachycardia, ICD: Implantable cardioverter-defibrillator, CABG: Coronary artery bypass graft, IV: Intravenously, CCB: Calcium channel blocker 
one fatal case per 783,972 hours. ${ }^{13}$ According to studies on the safety of cardiac rehabilitation, the frequency of cardiovascular-related complications is low: from once every 26,715 hours to once every 81,101 hours, depending on the investigator. In the case of fatal complications, the frequency has been reported to be very low, from once per 116,402 hours to zero. ${ }^{12-17}$

According to an observational study with 25,420 patients in 65 multiple institutions who were studied for a year, cardiovascular-related complications have been reported to be once per 8,484 times of graded exercise tests, and once per 49,565 exercise hours. ${ }^{18}$ The present authors have reported that cardiovascular-related abnormal responses occurred in 34 cases (1.4\%) during 2,429 exercise hours in the first year of the study, from January, 1999, when the cardiac rehabilitation clinic opened in the present medical institution, and that no fatal complications such as death, cardiac arrest or acute myocardial infarction occurred. ${ }^{8}$ While there were 70 cases of cardiovascular-related abnormal responses in 59 patients (1/199 exercise hours) in this study, no fatality or severe cardiovascular-related complication such as cardiac arrest or myocardial infarction occurred during the total exercise time of 11,612 hours $(0 / 11,612$ exercise hours).

As for why monitoring exercise for cardiac disease patients appears to be safe, we consider it to be due to the fact that the monitoring exercise was conducted only after the patient had been classified according to their exercise risk, the development of excellent pharmaceuticals and the appearance of a dazzling array of new methodologies and technologies for the diagnosis and treatment of cardiovascular-related diseases over the last few decades. Particularly, scrupulous monitoring of heart rate, blood pressure, perceived symptoms, etc. with wireless ECG that is conducted in real time during monitoring exercises is considered as playing a decisive role in the prevention of cardiovascular-related complications during the exercises. Longer-term results obtained through continued data collection from multiple institutions in the future are deemed necessary.

\section{CONCLUSION}

While early hospital-based monitoring exercises for cardiac rehabilitation may be safely implemented, that is, without the occurrence of fatal complications such as death, cardiac arrest or acute myocardial infarction, prior graded exercise tests and appropriate exercise prescription together with concentrated monitoring are absolute requirements in monitoring exercise programs.

\section{REFERENCES}

1. Taylor RS, Brown A, Ebrahim S, Jolliffe J, Noorani H, Rees K, Skidmore B, Stone JA, Thompson DR, Oldridge N. Exercise-based rehabilitation for patients with coronary heart disease: systematic review and meta-analysis of randomized controlled trials. Am J Med 2004; 116: 682-692

2. O'Connor GT, Buring JE, Yusuf S, Goldhaber SZ, Olmstead EM, Paffenbarger RS Jr, Hennekens CH. An overview of randomized trials of rehabilitation with exercise after myocardial infarction. Circulation 1989; 80: $234-244$

3. Anderson JL, Adams CD, Antman EM, Bridges CR, Califf RM, Casey DE, Chavey WE 2nd, Fesmire FM, Hochman JS, Levin TN, et al. ACC/AHA 2007 guidelines for the management of patients with unstable angina/non ST-elevation myocardial infarction: a report of the American College of Cardiology/American Heart Association Task Force on Practice Guidelines (Writing Committee to Revise the 2002 Guidelines for the Management of Patients wWth Unstable Angina/ Non ST-Elevation Myocardial Infarction): developed in collaboration with the American College of Emergency Physicians, the Society for Cardiovascular Angiography and Interventions, and the Society of Thoracic Surgeons: endorsed by the American Association of Cardiovascular and Pulmonary Rehabilitation and the Society for Academic Emergency Medicine. Circulation 2007; 116: 148-304

4. Antman EM, Anbe DT, Armstrong PW, Bates ER, Green LA, Hand M, Hochman JS, Krumholz HM, Kushner FG, Lamas GA, et al. ACC/AHA guidelines for the management of patients with ST-elevation myocardial infarction--executive summary. A report of the American College of Cardiology/American Heart Association Task Force on Practice Guidelines (Writing Committee to revise the 1999 guidelines for the management of patients with acute myocardial infarction). J Am Coll Cardiol 2004; 44: 671-719

5. Witt BJ, Jacobsen SJ, Weston SA, Killian JM, Meverden 
RA, Allison TG, Reeder GS, Roger VL. Cardiac rehabilitation after myocardial infarction in the community. J Am Coll Cardiol 2004; 44: 988-996

6. Niebauer J, Hambrecht R, Velich T, Hauer K, Marburger C, Kalberer B, Weiss C, Hodenberg E, Schlierf G, Schuler G, et al. Attenuated progression of coronary artery disease after 6 years of multifactorial risk intervention: role of physical exercise. Circulation 1997; 96: 2534-2541

7. Scott IA, Lindsay KA, Harden HE. Utilization of outpatient cardiac rehabilitation in Queensland. Med J Aust 2003; 179; 341-345

8. Kim C, Lim HS, Ahn JK, Lee SM, Bang IK, Kim YJ. Cardiovascular complications during cardiac exercise program. J Korean Acad Rehab Med 2002; 26: 797-801

9. AACVPR. Guidelines for cardiac rehabilitation and secondary prevention programs, 4 th ed, Champaign: Human Kinetics, 2004, 72

10. Paul-Labrador M, Vongvanich P, Merz CN. Risk stratification for exercise training in cardiac patients: do the proposed guidelines work? J Cardiopulm Rehabil 1999; 19: 118-125

11. Sohn JW, Lee JU, Yoon SN, Lee S, Kim KS, Kim JH, Lim $\mathrm{HK}$, Lee BH, Lee JK. Change in incidence and trends of cardiovascular diseases in Korean adults. Korean J
Intern Med 1995; 49: 802-813

12. Haskell WL. Cardiovascular complications during exercise training of cardiac patients. Circulation 1978; 57: 920-924

13. Van Camp SP, Peterson RA. Cardiovascular complications of outpatient cardiac rehabilitation program. JAMA 1986; 256: 1160-1163

14. Keteyian SJ, Mellett PA, Fedel FJ, McGowan CM, Stein PD. Electrocardiographic monitoring during cardiac rehabilitation. Chest 1995; 107: 1242-1246

15. Saner H, Saner B, Staubli R. Initial results with a comprehensive ambulatory rehabilitation program for heart patients. Schweiz Med Wochenschr 1994; 124: 2075-2082

16. Franklin BA, Bonzheim K, Gordon S, Timmis GC. Safety of medically supervised outpatient cardiac rehabilitation exercise therapy: a 16-year follow-up. Chest 1998; 114: 902-906

17. Vongvanich P, Paul-Labrador MJ, Merz CN. Safety of medically supervised exercise in a cardiac rehabilitation center. Am J Cardiol 1996; 15: 1383-1385

18. Pavy B, Iliou MC, Meurin P, Tabet JY, Corone S. Safety of exercise training for cardiac patients: results of the French registry of complications during cardiac rehabilitation. Arch Intern Med 2006; 166: 2329-2334 